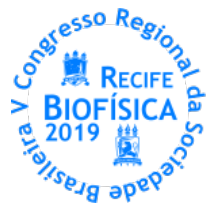

\title{
BIOPHYSICAL AND MORPHOLOGICAL OUTCOMES FROM UVAOL TREATMENT IN TROPHOBLAST CELLS INFECTED BY STREPTOCOCCUS AGALACTIAE
}

\author{
Aldilane Lays Xavier Marques ${ }^{1 *}$, Liliane Patricia Gonçalves Souza Tenorio ${ }^{1}$, Rayane Martins Botelho ${ }^{1}$, Ana Lucia \\ Mendes da Silva ${ }^{1}$, Julie Bergeron ${ }^{2}$, Guillaume Sébire ${ }^{2}$, Elaine Cristina Oliveira da Silva ${ }^{3}$, Samuel Teixeira Souza ${ }^{3}$, \\ Eduardo Jorge Silva Fonseca ${ }^{3}$, Alexandre Urban Borbely ${ }^{1}$, Karen Steponavicius Cruz Borbely ${ }^{1,4}$
}

${ }^{1}$ Cell Biology Laboratory, Institute of Health and Biological Sciences, UFAL, Brazil; 2Department of Pediatrics, Division of Neurology, Faculty of Medicine, McGill University, Montreal, Canada, ${ }^{3}$ Optics and Nanoscopy Group, Physics Institute, Federal University of Alagoas, Maceio, Brazil, ${ }^{4}$ Faculty of Nutrition, Federal University of Alagoas, Maceio, Brazil

*Aldilane.marques@icbs.ufal.br

\begin{abstract}
The streptococcus agalactiae, also known as group B streptococcus (GBS), is the main bacteria to cause chorioamnionitis, the inflammation of fetal membranes that can lead to abortion and prematurity. Olive oil consumption during pregnancy has been linked to various health benefits, as a potent anti-inflammatory and anti-oxidative natural product, which can help in preterm birth reduction. One of its components, the triterpene uvaol, is described as one main anti-inflammatory molecule within olive oil. As such, we aimed to analyze morphological and biophysical outcomes on trophoblast cells incubated with inactivated GBS. Methods: HTR-8/SVneo cells were used to represent first trimester trophoblast cells. They were pre-treated with uvaol and incubated with inactivated GBS. All groups were analyzed by MTT, cell death assay and falloidin staining, also using atomic force microscopy to analyze cell topography and membrane elastic properties. Results:
\end{abstract}

GBS at $10 x^{8}$ CFU reduced cell viability in MTT assay and increased cell death, while uvaol pretreatment was able to improve the viability loss caused by GBS at $10 x^{8}$ CFU. Falloidin staining and topography analyzes showed that cells deeply changed their morphology after GBS incubation, reducing actin polymerization and cytoplasm area, presenting themselves as rounded cells with higher rugosity, while uvaol failed to protect cells from these changes. The membrane elasticity was measured by Young's Modulus and GBS induce an increase on membrane elasticity, while uvaol helps to restore the original elasticity. Conclusion: Inflammation caused by inactivated-GBS support its deleterious effects on pregnancy. Uvaol protected trophoblast cells from death and restored membrane elasticity. Therefore, it could be thought to be an interesting natural compound to be taken during pregnancy in order to prevent placental dysfunctions and prematurity. 